\title{
The Playing Field Shifts: Predicting the Seats-Votes Curve in the 2008 U.S. House Elections
}

\section{by \\ Jonathan P. Kastellec, Columbia University \\ Andrew Gelman, Columbia University Jamie P. Chandler, City University of New York}

However, they were not able to overcome the Republicans' built-in advantage to obtain a majority of seats. The reasons for this advantage could be found largely in the difference between districts controlled by the two parties prior to the 2006 elections; some of this difference was due to geographic factors and favorable redistricting, and some to the Republicans' incumbency advantage. In 2006, the Democrats finally obtained a large enough share of the average district vote to overcome the partisan bias that the Republicans enjoyed and gain control of the House, winning 233 seats. $^{4}$

The shift in control of the House has meant a concomitant switch in incumbency advantage from the Republicans to the Democrats. As a result, even if every member serving at the beginning of the 110th Congress in 2007 were running for reelection, the Democrats would be in a vastly improved electoral position compared to 2006. Events in the last two years have benefited the Democrats even further. In three districts where Republican members resigned from their seats, Democratic challengers were able to win runoff elections, bringing the current seat total to $236.5^{5}$ More dramatically, 30 Republicans have either resigned or announced that they will not seek reelection in 2008, compared to only eight Democrats, meaning the former will have to defend many more open seats. ${ }^{6}$

This imbalance in retirements, coupled with the Democrats' gains in these runoff elections, reflects the broad dissatisfaction with the Republican Party currently held by the American public, due in large part to economic distress and the war in Iraq. While this disfavor is most clearly seen in President Bush's low approval ratings, it has also extended to House Republicans. Following the Democratic candidate's victory in a Mississippi special election in May, Tom Davis, a Republican member from Virginia and former head of the Republican National Congressional Committee, said, "The political atmosphere facing House Republicans this November is the worst since Watergate and is far more toxic than it was in 2006" (Nagourney and Hulse 2008). It is clear that the Republicans face an uphill fight in 2008.

\section{Predicting the Seats-Votes Curve}

We seek to quantify how much an advantage the Democratic Party is likely to enjoy by estimating the seats-votes curve for the 2008 elections. In the interests of space, we refer readers 


\section{Figure 1}

\section{Estimated Seats-Votes Curve}

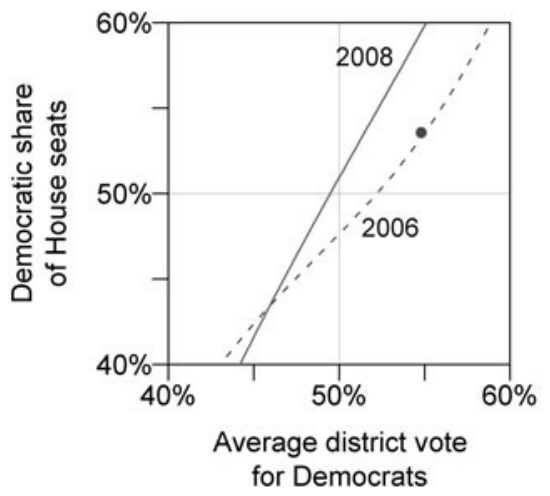

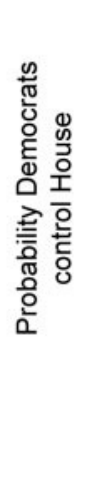

win across a range of possible national swings in the average district vote. ${ }^{7}$ As we demonstrated, the method was generally successful in predicting the actual translation between votes and seats in the 19 nonredistricting election years (those not ending in " 2 ") from 1958 to 2004. And in 2006, the seats-votes curve we estimated predicted that the Democrats would win 231 seats based on their actual average district vote of $54.9 \%$, just two short of the 233 they actually won.

As noted above, the shift in party control of the House now means that the Democrats enjoy an overall incumbency advantage. This advantage will be compounded by the imbalance in retirements, which has important implications for both the parties' expected vote shares and the relationship between seats and votes. For every Republican incumbent who retires, we can expect the Democratic vote share to increase by an estimated $8 \%$ in that district. ${ }^{8}$ Thus, assuming 30 Republicans retire (a total equal to $7 \%$ of all House seats), then the Democrats' overall vote share will increase by an estimated $0.56 \%$ - not a trivial amount. ${ }^{9}$ Figure 1 presents the estimated seats-votes curve for 2008 , along with the predicted probability that the Democrats control the House based on their average district vote. For comparison, we reproduce our estimates from 2006. The curves reveal that the electoral playing field has shifted significantly to the Democrats, who should benefit from a slight partisan bias in 2008. We estimate that if the Democrats win $50 \%$ of the average district vote, or about $5 \%$ less than they did in 2006, they will win about $51.4 \%$ of seats (or 224). to our earlier article for a thorough description of how we estiGelme seats-votes curve for a given election year (Kastellec, predicte (we leave this to national forecasts and polls), but distrit vote in hiven its average district vote in the elections. In brief, we incorporate districtlevel information, such as incumbency status and the vote percentage in the previous election, to generate a prediction of the number of seats the Democrats or Republicans can expect to
Average district vote for Democrats

Note: (1) Predicted seats-votes curve for 2006 (dotted line) and 2008 (solid line); the point depicts the actual average district vote for Democrats $(54.9 \%)$ in 2006 and their the House given their average district vote in 2006 (dotted line) and 2008 (solid line), respectively. Light lines are references for $10 \%, 50 \%$, and $90 \%$ probabilities.

\section{Figure 2} Average District Vote versus Percentage of House Seats for Democrats, 1946-2006, plus
2008 Projections of Democratic Seats Given Votes

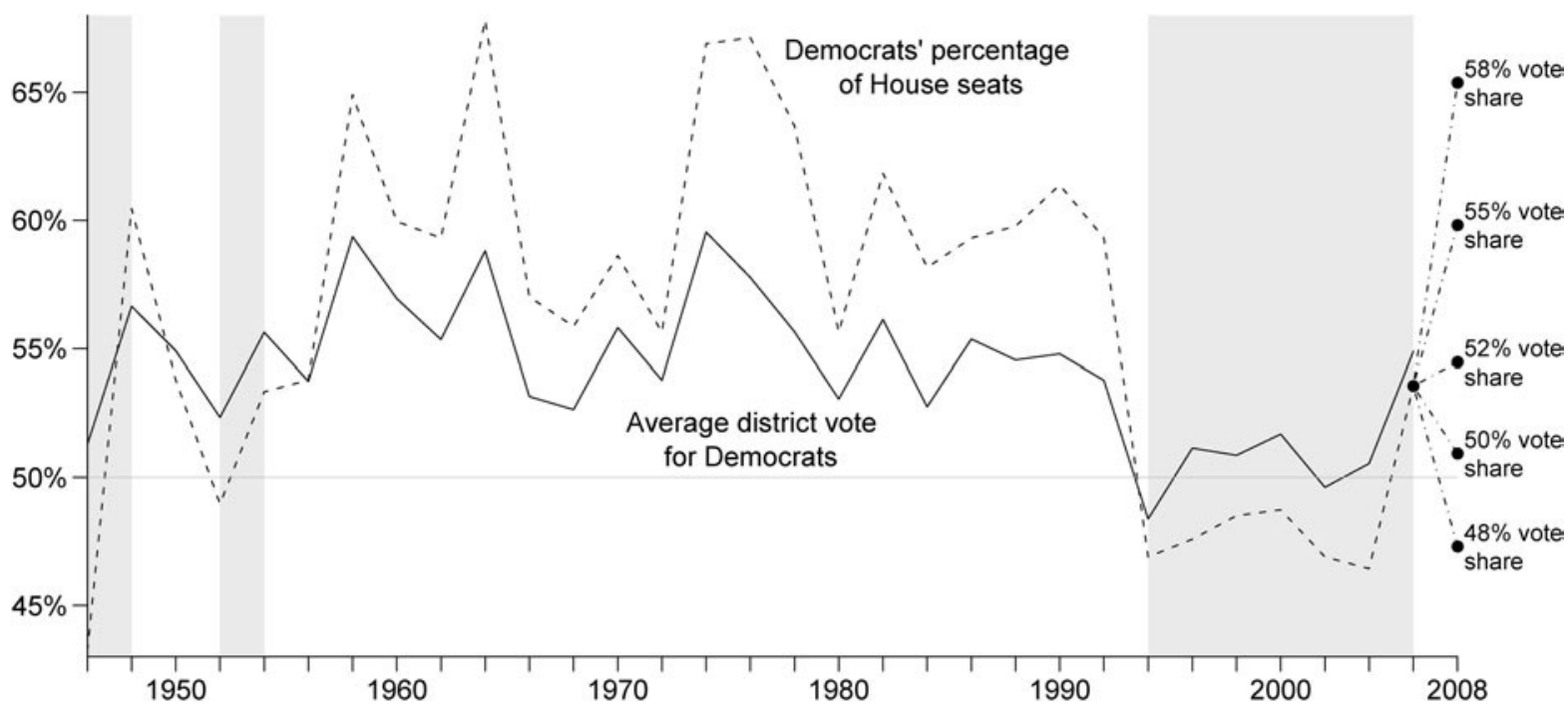

Note: The solid black line depicts the average district vote for Democrats in each House election from 1946 to 2006 . The dotted black line depicts the Democrats' share of House seats in the same period. The gray line is a reference for $50 \%$ of the vote. Shaded areas represent periods of Republican control. The five dotted lines at the end of the figure depict the projected number of seats the Democrats would win, if they received the average district vote given by the label next to each line. For instance, if they win $58 \%$ of the average district vote, we estimate that they will win approximately $66 \%$ of seats in the House. 
This partisan bias is not as large as what the Republicans enjoyed in 2006. In that election, we estimated that the Democrats would win only $48 \%$ of the seats if they won $50 \%$ of the average district vote, and that they needed to win $52 \%$ of the vote just to have a $50 \%$ chance of winning a majority. In actuality, the Democrats won $54.9 \%$ of the average district vote but only $53.6 \%$ of the seats.

The electoral terrain is more favorable to the Democrats in 2008. Figure 2 places this year's election in historical perspective, depicting the average district vote for Democrats as well as their share of House seats from 1946 to 2006. The Democrats enjoyed a large partisan bias during their 40-year reign over the House. The bias switched to the Republicans following their victory in 1994, and they enjoyed that advantage leading up to the 2006 elections. The dotted lines extending from the 2006 results depict our estimates of the seats the Democrats would win corresponding to five potential aggregate vote shares for the party: $48 \%, 50 \%, 52 \%, 55 \%$, and $58 \%$. For the latter four possibilities, the Democrats would win many more seats than votes, a return to the pattern seen during the 1970s and 1980s and a stark reversal from their electoral fortunes since 1994.

Another way to quantify this change is to predict how many seats the Republicans would have won in the elections from 1994 to the 2006 if the 2008 seats-votes curve had been in effect for those elections. That is, how many seats would the Republicans have obtained if their average district vote was translated into seats based on our estimate of the relationship between seats and votes in 2008? Figure 3 presents this counterfactual: the darker bars depict the actual seats the Republicans won, while the lighter bars depict the hypothetical number of seats they would have won under the estimated 2008 seats-votes curve (the numbers under each year show their average district vote from that year). As is readily apparent, except for 1994, the Republican's majority would have been a minority, and they would have obtained, on average, an estimated 20 fewer seats in the 1996-2004 period.

\section{Conclusion}

Following up on our analysis of the 2006 election, which saw the Democrats overcome a partisan bias in favor of the Republicans to gain a majority of House seats, we predicted the seatsvotes curve for the 2008 elections. Our analysis illustrates how
Figure 3

Actual versus Hypothetical Republican Results, 1994-2006

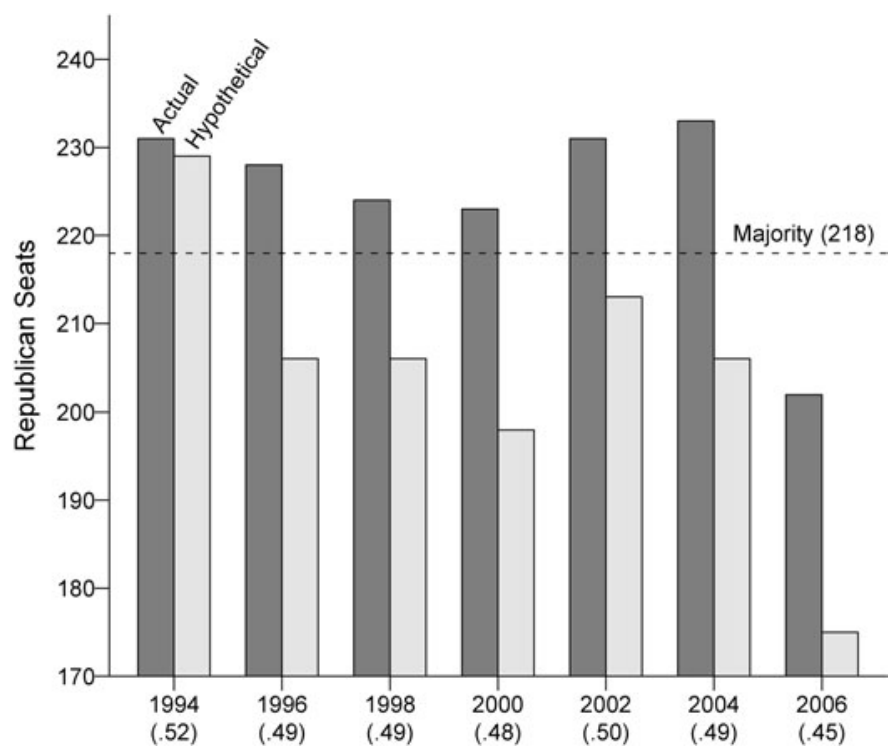

Note: The darker bars depict the actual seats the Republicans won, while the lighter bars depict the hypothetical number of seats they would have won under the 2008 estimated seats-votes curve. The numbers under each year show their average district vote in a given year. The horizontal dotted line depicts the number of seats (218) needed for a majority. The disagreement between actual and hypothetical does not represent a failure of our model but rather indicates changes in the seats-votes curve from election to election.

the shift in incumbency advantage to the Democrats, coupled with a large number of retirements on the Republican side, has shifted the electoral landscape in favor of the Democrats. While their advantage will likely not be as large as that held by the Republicans in 2006, this shift combined with favorable political conditions now means that the Democrats will likely pick up House seats this November and also will likely win more seats than votes for the first time since 1992.

\section{Notes}

* Replication datasets and statistical code are available at www.columbia. edu/ jpk2004/house2008.html. This webpage will also contain updated analyses incorporating any changes that occurred after we submitted this article at the end of July, such as primary defeats and information on uncontested races.

1. Polling results were obtained from Real Clear Politics's generic congressional vote webpage: www.realclearpolitics.com/epolls/other/generic_ congressional_vote-901.html\#polls.

2. Partisan bias is not necessarily due to gerrymandering-after all, the districts in 2008 are the same as they were two years ago-but rather represents a combination of all systemic factors that benefit one party or another in terms of seats given votes.

3. See Kastellec, Gelman, and Chandler $(2008,141)$ for a description of why we summarize election results using average district vote rather than total vote.

4. We follow Gelman and King (1994) in defining partisan bias as the expected percentage of seats over $50 \%$ a party obtains if they receive exactly half the average district vote. It is mathematically equivalent to note that there is partisan bias if the Democrats need more (or less) than half of the two-party vote in order to have an even chance at winning a majority of the seats in the House. In 2006, we predicted that Democrats needed to ob-

tain $52 \%$ of the average district vote to have a $50 \%$ probability of winning a majority of seats.

5. The three districts are Illinois' 14th district, the seat of former House Speaker Dennis Hastert, Louisiana's 6th district, and Mississippi's 1st district.

6. In addition, three members from each party died during the congressional session, while two Republicans-Wayne Gilchrest (MD-1) and Chris Cannon (UT-3) — and one Democrat-Albert Wynn (MD-4) — have been defeated in a primary.

7. Data on incumbency status and lagged vote was drawn from our 2006 analysis. Data on retirements and resignations was collected by referring to state election web sites and various news sources. The results in the paper are based on information available as of July 27, 2008. Because data on uncontested seats were not available at this point, we assumed that all races would be contested.

8. This estimate of the incumbency advantage, which we use in our seats-votes forecasting model, is based on Gelman and Huang (forthcoming), who use a multilevel model that allows incumbency advantage to vary between individual incumbents.

9. Assuming eight Democrats retire, this will offset the gain by about $0.16 \%$ 


\section{References}

Bafumi, Joseph, Robert S. Erikson, and Christopher Wlezien. 2007. "Forecasting House Seats from Generic Congressional Polls." Legislative Studies Section Newsletter 30 (1). www.apsanet.org/ lss/Newsletter/ jan07/EOR.pdf.

Gelman, Andrew, and Gary King. 1994. "A Unified Method of Evaluating Electoral Systems and Redistricting Plans." American Journal of Political Science 38 (2): 514-54.

Gelman, Andrew, and Zaiyang Huang. Forthcoming. "Estimating Incumbency Advantage and its Variation, as an Example of a BeforeAfter Study." Journal of the American Statistical Association.

Intrade.com. 2008. "2008 US House of Representatives Control. The Democrats to Control the House of Representatives after 2008 Congressional
Elections." www.intrade.com/jsp/intrade/common/c_cd.jsp? conDetailID $=431080 \& z=1151003209000$.

Kastellec, Jonathan P., Andrew Gelman, and Jamie P. Chandler. 2008. "Predicting and Dissecting the Seats-Votes Curve in the 2006 U.S. House Election." PS: Political Science and Politics 41 (January): 139-45.

Klarner, Carl. 2008. "Forecasting the 2008 U.S. House, Senate, and Presidential Elections at the District and State Level." PS: Political Science and Politics 41 (October): 723-28.

Lockerbie, Brad. 2008. "Election Forecasting: The Future of the Presidency and the House." PS: Political Science and Politics 41 (October): 713-16. Nagourney, Adam, and Carl Hulse. 2008. "Republican Election Losses Stir Fall Fears." The New York Times, May 15. 